This is a pre-print of an article published in Innovations in Education and Teaching International. The final authenticated version is available online at:

Gil-Doménech, D.; Berbegal-Mirabent, J. (2020). Making the learning of mathematics meaningful: An active learning experience for business students. Innovations in Education and Teaching International, 57(4): 403-412. https://doi.org/10.1080/14703297.2020.1711797

\title{
Making the learning of mathematics meaningful: An active learning experience for business students
}

\section{Dolors Gil-Doménech* and Jasmina Berbegal-Mirabent}

Department of Economy and Business Organisation, Universitat Internacional de Catalunya, Barcelona, Spain

\begin{abstract}
Mathematics is presented in non-STEM disciplines as a subject that helps students acquire tools they will need in their future careers. Therefore, the need for instruction in mathematics demands content, oriented not only towards fundamental principles and techniques, but also towards their application in a specific context. By directing the teaching in this sense, students are able to recognise the relevance of mathematics and the possibilities that this subject offers. The purpose of this paper is thus to propose a methodology for making the learning of mathematics meaningful for non-STEM students. We illustrate its implementation by presenting an activity that requires business university students to search for economic applications of the concepts learned in a course of mathematics. As students' involvement is envisaged, the activity incorporates an active learning methodology that aims to promote the acquisition of hard and soft skills. Results obtained from its application are reported and discussed.
\end{abstract}

Keywords: mathematics education, higher education, active learning, hard and soft skills, economic applications

\section{Introduction}

Mathematics is the science of patterns and relationships (AAAS 1994). Yet, students and particularly those in non-STEM (Science, Technology, Engineering and Mathematics) programmes might find difficult to engage in such a subject. In this regard, the content of 
mathematics has to be understood as a link between what students learn in class and what they apply in industry (Hahn 2014). To ensure that students learn how to apply mathematics to specific problems, it is not sufficient teaching them the formal content, but to expose them to situations where the knowledge acquired is put into practice (Martín and Zavala 2006). Only by facing problems, they are able to fully understand and value the importance of subjects such as mathematics.

In the field of economics, both mathematic and economic methods may be combined, such as, for example, when analysing processes, looking for optimal decisions, or predicting results. In universities, where economic disciplines are taught, the need for a functional component of mathematics demands content, oriented not only towards fundamental principles and techniques but also towards their application in an economics context. To achieve this goal, lecturers are expected to explain the economic meaning of mathematical concepts, while giving examples of areas where these concepts may be applied (Mardanov and Khasanova 2014).

Rooted in this context this study aims at contributing to the existing literature by further examining how students in non-STEM disciplines can be more engaged with mathematics. As suggested by previous studies (Freeman et al. 2014), we discuss an active learning activity that is expected to increase students' interest and achievements in mathematics.

We define active learning as any instructional method that engages students in the learning process, requiring them to think while performing meaningful activities (Sesen and Tarhan 2011). Given that university education should foster lifelong learning (Kember 2009), the suggested activity is designed in such a way as to enhance students' skills. On the one hand, hard skills (technical abilities) are introduced by obliging students to apply mathematics in the economic field. On the other hand, the activity boosts several soft (transversal) skills. 
Specifically, teamwork is promoted by having students working in groups. The capacity for finding information is nurtured by requiring students look for economic applications. Digital skills are developed through the use of an online platform (for the delivery of the activities) and the Internet (as a source of information). Finally, personal responsibility is hastened by requiring students to self-evaluate in terms of participation, punctuality, attendance and attention.

\section{Literature review}

Mathematics provides students with the capacity to solve different problems in a diversity of situations, thereby increasing their autonomy. According to Cano and Berbén (2009), lecturers in mathematics need to be concerned, not only about the subject itself, but also about the way students experience learning. Existing literature in the field of teaching practices for mathematics at higher education distinguishes between works that examine how this subject should be taught, from those that concentrate on the effect of different teaching methods in students' attitudes and achievements.

With respect to studies on teaching methods for mathematics, Pritchard (2010), similar to Sfard (2014), highlighted the benefits of the traditional methods, acknowledging that they could be reinforced by other activities. Following this reasoning, Chaerani and Dewanto (2014) observed that active learning was a useful pedagogical technique, and Naik (2017) went a step further and analysed game-based learning, concluding that the learning experience and outcomes are improved.

A second cadre of academics has investigated the attitudes to mathematics and achievements of learners. For instance, Alkhateeb and Hammoudi (2006) found that, enlightened approaches to learning - focused, not only on replicating but on understanding imply a higher degree of self-confidence and a greater responsibility for the student. In a 
similar vein, Cano and Berbén (2009) assessed the conceptions of mathematics of university students and observed a positive relationship between approaches to learning and perspectives on the achievement of goals.

Putting together the previous findings, it can be concluded that in order to make the learning of mathematics meaningful and improve students' attitudes, courses ought to be designed using active leaning methods and include activities in which students go beyond the mere understanding, and thus, apply the new knowledge to analyse, synthesise and/or evaluate real-world situations. This approach has been found to be particularly suitable in non-STEM disciplines as students tend to be less self-confident and consider this subject very complex and far from their future careers. To achieve this goal, the teaching needs to be professionally oriented, which implies the need to include an economic/managerial meaning to the mathematical concepts taught (Mardanov and Khasanova 2014). Moreover, endowing the teaching with meaning has been found to stimulate motivation, as students are able to understand the usefulness of the content, connect it to their future lives - when at the workplace - and consequently more easily engage in the learning process (Mardanov and Khasanova 2014). In turn, such an attitude might probably translate into better academic records (Kuh 2016).

Despite literature in the field of the teaching of mathematics in higher education being rich, there is a lack of studies that tackle the issue of how to teach mathematics in non-STEM curricula using active learning methods. This is especially important in the fields of economics or business, where mathematics is not the core subject, but its foundations are essential for the correct interpretation of many daily phenomena. Additionally, previous research argues that students have difficulties in the reading and understanding of mathematical concepts (Shepherd, Selden and Selden 2012) and that they lack self-motivation (Faulkner and Whalley 2017). 
Given the above considerations, an active learning activity is designed.

\section{Description of the activity}

\section{Main purpose}

The activity proposed asks students to look for economic applications of the concepts introduced in the subject of Mathematics 1, taught in the first course of the Bachelor's Degree Programme in Business Administration at the Universitat Internacional de Catalunya (Barcelona, Spain). The ultimate purpose is to make students aware that mathematical concepts are going to be useful in their daily activities as business professionals. While other active learning methodologies might have been selected, the rationale behind our choice is twofold. First, it serves as an introduction to other methodologies based on problems and projects. Second, it complements current approaches by making students look for the problems to solve. Said differently, the activity described here corresponds to the highest level of Bloom's (1956) taxonomy, in which students have to "create" and "solve" a problem, which implies a deeper level of understanding. Students are required to work in teams, to look for information, and to use new technologies. The activity has a marked voluntary character.

\section{Background}

During the 2013/2014 academic year, 69 students enrolled in Mathematics 1 were asked to give their feedback. Opinions were collected through an open anonymous questionnaire. The objective was to identify the main challenges students encountered, and thus, be able to redesign some parts of the syllabus and overcome the drawbacks raised. Table 1 summarises the responses obtained, and the percentages associated with each response. Based on their opinions some opportunities for improvement were identified, being one of them the design of the activity presented here. Table 1 also shows the main characteristics of this activity, and 
the strengths (weaknesses) that each characteristic enhanced (overcame).

Insert Table 1 about here

A pilot activity was launched in 2014/2015. Students positively evaluated it and suggested some further ideas such as taking in consideration their involvement and personal responsibility. Minor changes were introduced and a series of questionnaires ${ }^{1}$ were designed. The activity was repeated during the academic year 2015/2016. Results from this most recent edition are reported in the next sections.

\section{Sample}

The sample comprises students from two classes with 38 and 49 students, respectively. The activity was developed during the final days of the course after all the content had been covered. Students were asked to enrol via the online platform of the course. Of the 87 eligible students, $72(83 \%)$ participated, 30 from one class and 42 from the other, from which 12 (40\%) and $18(43 \%)$ were female, respectively. Students, in the first case, were grouped into six teams of five, and, in the latter case, into seven teams of six. In order to promote cooperation and ensure a shared level of mathematical knowledge between the different teams, students were grouped according to their average grades in the continuous evaluation and in the mid-course exam. Two additional criteria were applied: gender-balance and the grouping of students with classmates with whom they did not usually work with.

\section{Detailed description}

Students were asked to find one particular economic application (statement and resolution) for each of the four chapters included in the syllabus. The four exercises could be taken from

\footnotetext{
${ }^{1}$ Questionnaires are available upon request to authors.
} 
multiple sources or made up, but were to be different from the exercises done in class.

Insert Table 2 about here

Table 2 summarises the different sub-tasks in which the activity was divided. On the first day, after the explanation of the activity and its objectives, students were grouped and started a first team discussion. They also chose a team leader, who became the person responsible for submitting the final work. From the works submitted, the lecturer selected the best exercises to illustrate each chapter. During the following four days, the original statements were projected on the screen and a member of the team - randomly designated by the instructor - solved and explained it on the blackboard. To promote attention, at least one of all the exercises was to be included in the final exam. On the last day of class, each team had to both evaluate itself and the other teams according to a rubric (by filling in questionnaire \#1).

The assessment was based on four dimensions: quality of the exercises - in terms of originality and difficulty $-(40 \%)$, resolution $(40 \%)$, and personal responsibility (10\%). By applying these percentages, the lecturer's grade was obtained. The remaining $10 \%$ was the average peers' evaluation. Accordingly:

$$
\text { Grade }=\text { Lecturer's evaluation }+10 \% \cdot \text { Average peers' evaluation }
$$

The teams that ranked among the top 50\% were awarded two extra points in the continuous evaluation grade, while the rest of the groups were awarded one extra point. In order to promote individual responsibility, provision was made for deduction of the extra points awarded if a student did not answer a questionnaire, arrived late, or was unjustifiably absent. 


\title{
Results
}

\section{Examples of economic applications}

Table 3 reports some examples of the economic applications presented. The majority of exercises were taken from the Internet or made up, although in some few cases students also used books.

\author{
Insert Table 3 about here
}

\section{Performance}

The main results of the activity are summarised in Figure 1 for all 13 teams. Specifically, it illustrates the grades (from 1 to 5) from the lecturer's assessment, and self- and peerevaluation (these latter collected through questionnaire \#1).

Insert Figure 1 about here

As it can be observed, in nine cases $(69.2 \%)$, the best evaluation corresponded to the self-assessment, suggesting that students were more enthusiastic about their own work than the work of others. However, when it came to evaluating their classmates, they were more stringent. It is also worth highlighting that students typically considered their work to be much better than what it actually was (except for groups I and J), being group F the one showing the highest dispersion between students' and lecturer's scores.

The final exam included four questions referring to economic applications (one for each chapter). The maximum score a student could get in this part was 4 points ( 1 per question). Scores ranged between 0 and 1, based on the degree of accuracy in the answer. To 
provide evidence on how helpful was the activity in improving students' understanding, Table 4 displays the average scores obtained in the final exam for questions 1 to 4 .

Insert Table 4 about here

Data reveals that before introducing the activity (2013/2014 course) students found serious problems in correctly solving these exercises. Thanks to the activity grades have substantially improved, suggesting its usefulness in the acquisition of this specific hard skill. The only exception is found in chapter 4 . In this case the activity seems to add little value. Also, it can be noted that, while in 2014/2015 the grades in chapter 1 improved, the subsequent academic year they decreased, being slightly above the initial values. Future editions might consider collecting qualitative data (i.e. through interviews or focus groups) to shed light on the rationale behind the trends.

\section{Engagement}

Students were also asked to answer questionnaire \#2, in which each student had to evaluate his/her and the other team members' involvement using a 5-point scale. Figure 2 shows the results. Given that the average evaluations were fairly high and with small variations, it can be concluded in all teams, all members were similarly contributing.

Insert Figure 2 about here

\section{Students' feedback}

Finally, Figures 3 and 4 show students' opinions (frequency and percentage) regarding the learning strategy, the methodology used, and the acquisition of soft and hard skills. 
Insert Figure 3 about here

Insert Figure 4 about here

From all the items included in the survey, scores were near 4 in a scale from 1 to 5 (even for the ones evaluated with the lowest score), revealing that students were notably satisfied regarding the degree of skills acquisition, and that the learning strategy and methodology used was appropriate. As Figure 3 illustrates, students confirm that the activity was helpful to understand the main concepts taught. However, there is still room for improvement in the way teams performed in order to make collaboration with other students more useful for knowledge acquisition. Yet, this result should be interpreted with caution, as Figure 4 indicates that students are confident working in teams. Therefore, we can conclude that teamwork can be developed through this activity. In addition, results indicate that students also felt responsible during the development of the activity, being this skill the one with the highest average score.

\section{Discussion}

The main objective of this study was to design, implement and analyse the results of an activity that is expected to make the learning of mathematics more meaningful to non-STEM students.

The original value of this work is threefold. First, it focuses on non-STEM disciplines, while most of the studies tackling the issue of how to teach mathematics at university level do so in the STEM curricula. Second, the activity intends to go beyond rote learning and instead, promotes deep understanding and the acquisition of soft skills. Finally, it aims at connecting the learning of mathematics with the economic reality. The combination of these two last principles has been found to motivate students and provide a more meaningful learning. 
Based on students' feedback and how the sessions developed, some ideas for improvement are envisioned. First, students reported some difficulty in doing the work within the given time constraint. If, from the very beginning of the course, students are informed, they will be able to think about potential economic applications during the entire duration of the course, while the concepts are actually being developed.

As for the deadlines to complete the questionnaires, students indicated that the time allocated was limited. They will be given more time in the future.

As for the method of delivery, the online platform could be used for the distribution of the exercises instead of the e-mail. This would also prevent students submitting their works after the deadlines.

\section{Concluding remarks}

This study aims at contributing to the existing debate about teaching mathematics to nonSTEM students. First, we argue that teaching practices should go a step further than one-way traditional learning and include curricula oriented activities that make students realise that what they are learning is relevant for their future professions. Quoting Alsina (2001, p. 8), "contents are not ends in themselves but means to ensure efficient knowledge". Accordingly, we posit that enriching the teaching with examples and real applications is imperative. Such an approach not only helps students better understand the content but also stimulates their interest in the subject and shows them how to use what they learn in their day-to-day lives.

Second, our study also connects with the stream of the literature that advocates for the use of active learning methodologies (Michael 2006). We contribute to this body of research by suggesting a new strategy, that of having students searching and solving their own exercise. The rationale behind it is requiring students to dive deeper in the concepts they are learning, and ask them to "create" or "search" rather than just "solve". This strategy has been found to be useful and can be later complemented with other active learning methods. As 
there is a wide variety of active learning methods, it is important to know how to combine and mix them up in order to effectively prepare students for their future careers and lives. Yet, for this to take place institutions need to be prepared, and provide mathematics educators with the necessary tools and skills to ensure an efficient teaching.

Although we believe this work provides useful insights, it presents some limitations that might open up new research lines. First, the application of the activity considers only 72 students from a specific university. Future studies might expand this sample and compare the results with the ones presented here. Also, although the activity aims at showing students the application of mathematics in a real context, the exercises solved were not taken from reality. Further research efforts should be done in order to go a step forward, trying to incorporate real economic problems. Finally, the measurement of skills' improvement is based on students' self-appraisal perceptions; therefore, results might be interpreted with caution biased. The use of alternative - and more objective - metrics such as validated scales is highly recommended for future studies. The assessment of soft skills still remains as one of the most complex and challenging issues for educators (Gibb 2014).

We hope that the results obtained encourage lecturers to design activities that increase students' interest and broaden their knowledge. There is a need for applying similar teaching methodologies in mathematical courses to non-STEM programmes. For instance, bachelor degree programmes such as Economics or Business Administration rely heavily on mathematical applications; however, students are not usually aware of this fact and find it hard to pass mathematics courses.

\section{References}

American Association for the Advancement of Science. (1994). Benchmarks for science literacy. New York: Oxford University Press.

Alkhateeb, H. M., \& Hammoudi, L. (2006). Attitudes toward and approaches to learning first- 
year university mathematics. Perceptual and Motor Skills, 103, 115-120.

Alsina, C. (2001). Why the professor must be a stimulating teacher. Towards a new paradigm of teaching mathematics at university level. In D. Holton (Ed.), The Teaching and Learning of Mathematics at University Level: An ICMI Study (Vol. 7, pp. 3-12). Netherlands: Kluwer Academic Publishers.

Bloom, B. S., Engelhart, M. D., Furst, E. J., Hill, W. H., \& Krathwohl, D. R. (1956). Taxonomy of educational objectives: The classification of educational goals. Handbook I: Cognitive domain. New York: David McKay Company.

Cano, F., \& Berbén, A. B. G. (2009). University students' achievement goals and approaches to learning in mathematics. The British Journal of Educational Psychology, 79, 131-153.

Chaerani, D., \& Dewanto, S. P. (2014). Active learning based on research for Linear Optimization course at Department of Mathematics, Universitas Padjadjaran. International Conference on Advances in Education Technology (ICAET), 58-61.

Faulkner, D., \& Whalley, F. (2017). Is numeracy my business? Investigation into improving numeracy for Level 4 Business students. In Rowlett, P., \& Waldock, J. (Ed.), Employability development for HE mathematics and statistics: case studies of successful practice. Sheffield Hallam University.

Freeman, S., Eddy, S. L., McDonough, M., Smith, M. K., Okoroafor, N., Jordt, H., \& Wenderoth, M. P. (2014). Active learning increases student performance in science, engineering, and mathematics. Proceedings of the National Academy of Sciences, 111(23), 8410-8415.

Gibb, S. (2014). Soft skills assessment: Theory development and the research agenda. International Journal of Lifelong Education, 33(4), 455-471.

Hahn, C. (2014). Linking academic knowledge and professional experience in using statistics: A design experiment for business school students. Educational Studies in Mathematics, $86,239-251$.

Kember, D. (2009). Nurturing generic capabilities through a teaching and learning environment which provides practise in their use. Higher Education, 57(1), 37-55.

Kuh, G. D. (2016). Making learning meaningful: Engaging students in ways that matter to them. New Directions for Teaching and Learning, 2016(145), 49-56. 
Mardanov, R., \& Khasanova, A. (2014). Current issues of teaching mathematics in economic faculties of universities. Procedia - Social and Behavioral Sciences, 152, 1062-1065.

Martín, M. Á. C., \& Zavala, J. C. N. (2006). Entrenamiento de alumnos de educación superior en estrategias de aprendizaje en matemáticas. Psicothema, 18(3), 348-352.

Michael, J. (2006). Where's the evidence that active learning works? Advances in Physiology Education, 30(4), 159-167.

Naik, N. (2017). The use of GBL to teach mathematics in higher education. Innovations in Education and Teaching International, 54(3), 238-246.

Pritchard, D. (2010). Where learning starts? A framework for thinking about lectures in university mathematics. International Journal of Mathematical Education in Science and Technology, 41(5), 609-623.

Sesen, B.A., \& Tarhan, L. (2011). Active-learning versus teacher-centered instruction for learning acids and bases. Research in Science \& Technological Education, 29(2), 205226.

Sfard, A. (2014). University mathematics as a discourse - why, how, and what for? Research in Mathematics Education, 16(2), 199-203.

Shepherd, M. D., Selden, A., \& Selden, J. (2012). University students' reading of their firstyear mathematics textbooks. Mathematical Thinking and Learning, 14(3), 226-256. 


\section{Tables and Figures}

Table 1. Relationship between strengths and weaknesses expressed by students, and, characteristics of the activity.

\begin{tabular}{|c|c|c|}
\hline Students' opinions & Frequency $(\%)$ & How students' opinions are addressed \\
\hline Continuous evaluation process & $19(43 \%)$ & $\begin{array}{l}\text { Participating in the activity has an } \\
\text { impact on the continuous evaluation } \\
\text { grading }\end{array}$ \\
\hline Final review of the content & $13(30 \%)$ & $\begin{array}{l}\text { The activity comprises exercises from } \\
\text { all the chapters }\end{array}$ \\
\hline Practical exercises & $9(20 \%)$ & $\begin{array}{l}\text { The exercises are practical } \\
\text { applications of mathematics }\end{array}$ \\
\hline Team working & $8(18 \%)$ & Students work in teams \\
\hline $\begin{array}{l}\text { Lack of examples of economic } \\
\text { applications }\end{array}$ & $15(34 \%)$ & $\begin{array}{l}\text { It consists of looking for exercises on } \\
\text { economic applications }\end{array}$ \\
\hline $\begin{array}{l}\text { Different difficulty level in the final } \\
\text { exam with respect to the exercises } \\
\text { done in class }\end{array}$ & $6(14 \%)$ & $\begin{array}{l}\text { At least one exercise from the activity } \\
\text { is included in the final exam }\end{array}$ \\
\hline $\begin{array}{l}\text { Need for higher level of student } \\
\text { participation }\end{array}$ & $4(9 \%)$ & $\begin{array}{l}\text { It is a voluntary task, and students are } \\
\text { asked to solve exercises on the } \\
\text { blackboard }\end{array}$ \\
\hline
\end{tabular}

Table 2. Description of the activity.

\begin{tabular}{cl}
\hline Order & \multicolumn{1}{c}{ Sub-task } \\
\hline 1 & Students enrol on-line for the activity \\
2 & The lecturer explains the activity and specifies the teams. There is a first \\
& team discussion with a brainstorming exercise \\
3 & Students send the work via e-mail and answer the questionnaire \#2 on-line \\
4 & In class the resolution of exercises in Chapter 1 is completed \\
5 & In class the resolution of exercises in Chapter 2 is completed \\
6 & In class the resolution of exercises in Chapter 3 is completed \\
7 & $\begin{array}{l}\text { In class the resolution of exercises in Chapter } 4 \text { is completed and teams } \\
\text { answer the questionnaire \#1 }\end{array}$ \\
8 & Students answer the questionnaire \#3 on-line \\
\hline
\end{tabular}


Table 3. Examples of economic applications suggested by students.

\begin{tabular}{ll}
\hline \multicolumn{1}{c}{ Chapter } & \multicolumn{1}{c}{ Examples } \\
\hline & $\begin{array}{l}\text { JL \& Co. produces computers. The selling price is } 500 € \text { per unit. Each year } \\
\text { the company spends 2,000€ in electricity and } 100,000 € \text { in wages. The unitary } \\
\text { variable cost is } 100 € \text {. Given this information: } \\
\text { 1. Determine the number of computers to sell in order to maximise the } \\
\text { profit. }\end{array}$ \\
$\begin{array}{l}\text { 1: Real functions of } \\
\text { one variable }\end{array}$ & $\begin{array}{l}\text { 2. If the company expects to sell } 100 \text { units, which is the estimated } \\
\text { profit? }\end{array}$ \\
3. The company wants to invest $50 \%$ of the profit calculated in (2). \\
They have two options: a) UIC Bank offers them a simple interest \\
with an interest rate of $3 \%$ in 5 years; b) ADE Bank offers them a \\
composed interest with an interest rate of $2 \%$ in 5 years. Which \\
option would you recommend? Justify the answer.
\end{tabular}

Given the following demand and supply functions of a particular commodity:

2: Integration $\quad Q_{d}=-P^{2} / 4+400, Q_{s}=P^{2} / 2-275$

1. Find the price and quantity that correspond to the equilibrium point.

2. Find the consumer and producer surpluses at the equilibrium point.

ParsleyTextile Inc. produces three types of textiles: trousers, shirts and T-
shirts. Its profit function is given as $\operatorname{Pr}(x, y, z)=2 x^{2}+y^{2}+4 z^{2}+6 x y-2 y z$
where $x, y$ and $z$ represent, the number of trousers, shirts and T-shirts,
respectively.
1. Will ParsleyTextile Inc. have losses?
2. If the company doubles the quantity of trousers produced, will it
obtain losses?
3. If the company decides to produce three times more shirts than T-
shirts, will it obtain losses?

In January 2015, the inventory of Berca Ltd. Included 30,000 tons of raw materials. During 2015 the company consumed 1,000 of these tons. Suppose that the forthcoming years (starting in 2016) the consumption of raw material will diminish at a $2 \%$ rate.

4: Numerical sequences and series
1. Will the raw material last forever? If not, calculate the year in which Berca Ltd. Would run out of raw materials.

2. Write the general term and the associated series of the consumption of raw material.

3. Study the tendency and behaviour of the sequence and the associated series obtained in (2). 
Table 4. Average grades obtained in the exercises of economic applications included in the final exam.

\begin{tabular}{cccc}
\hline Chapter & $2013 / 2014$ & $2014 / 2015$ & $2015 / 2016$ \\
\hline 1 & 0.41 & 0.63 & 0.46 \\
2 & 0.14 & 0.30 & 0.42 \\
3 & 0.47 & 0.51 & 0.68 \\
4 & 0.37 & 0.38 & 0.37 \\
$\Sigma$ & 1.29 & 1.82 & 1.93 \\
\hline
\end{tabular}

Figure 1. Summary of the results obtained from questionnaire \#1.

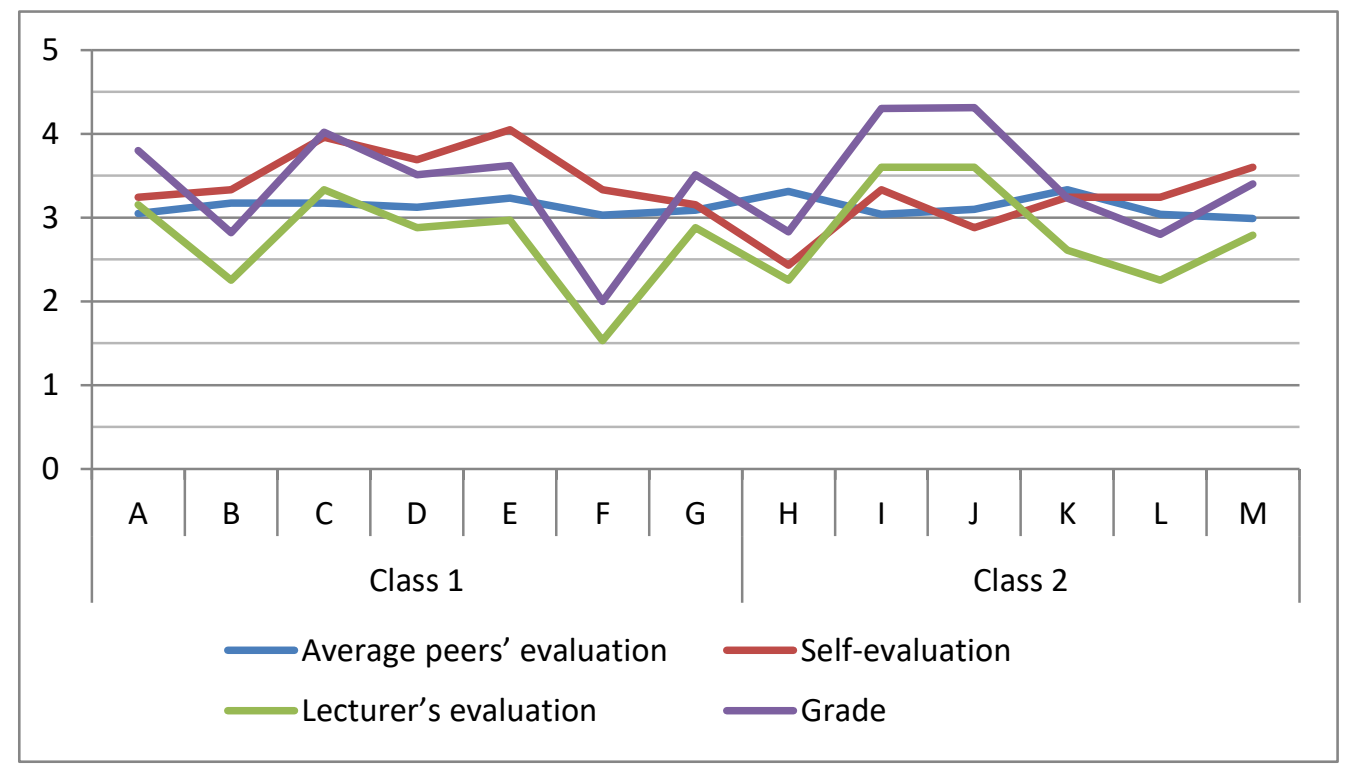

Figure 2. Summary of the results obtained from questionnaire \#2.

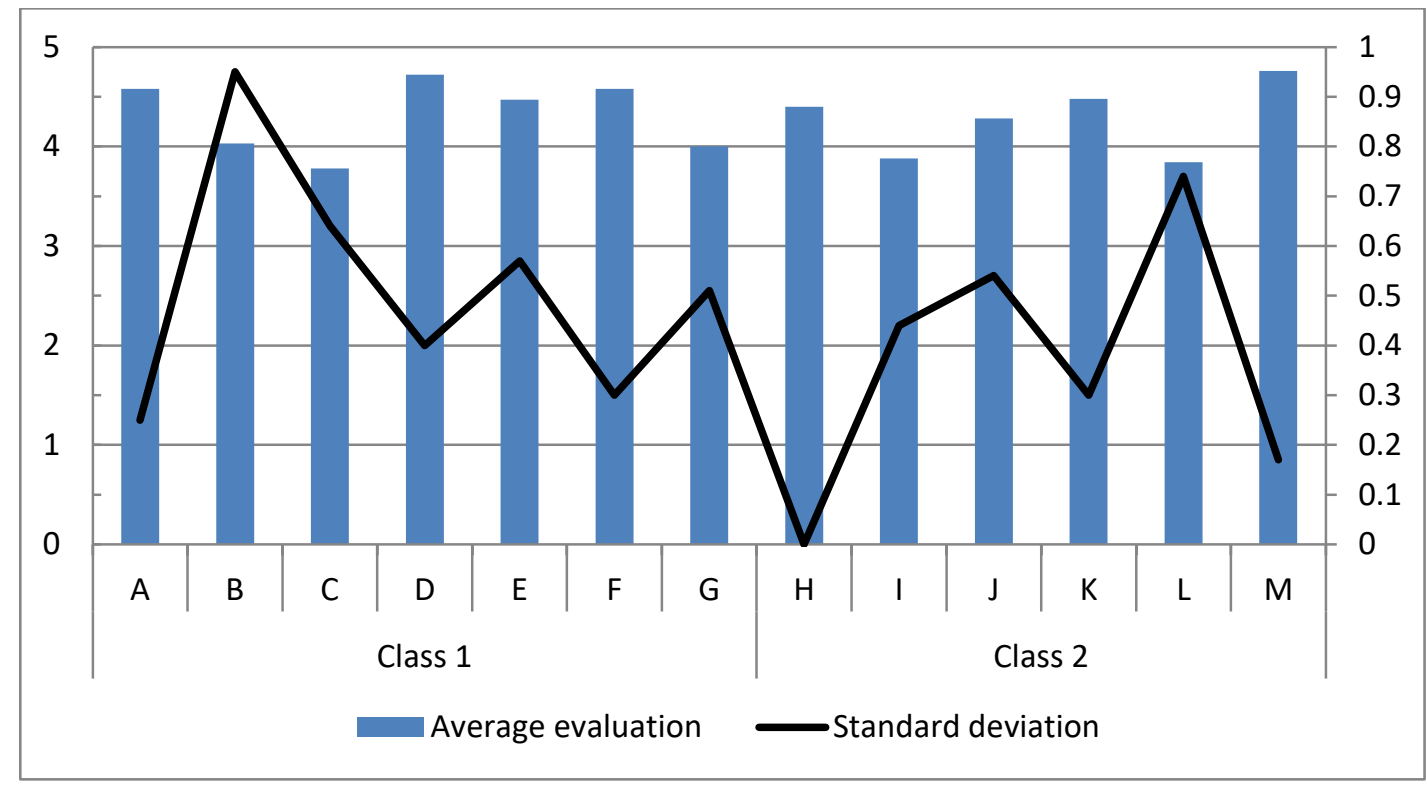


Figure 3. Results obtained from questionnaire \#3, Part A (learning, methodology and hard skills acquisition).

Do you consider the activity useful?

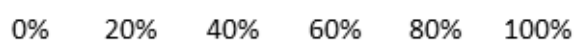

Do you think the fact that the activity incorporated economic applications has helped you to understand the concepts of Mathematics 1?

Do you think that, in general, it is useful to do economic applications of the concepts of Mathematics 1?

With respect to the activity, was your task clear for you?

Do you think the fact that the activity was in teams has helped you to understand the concepts of Mathematics 1?

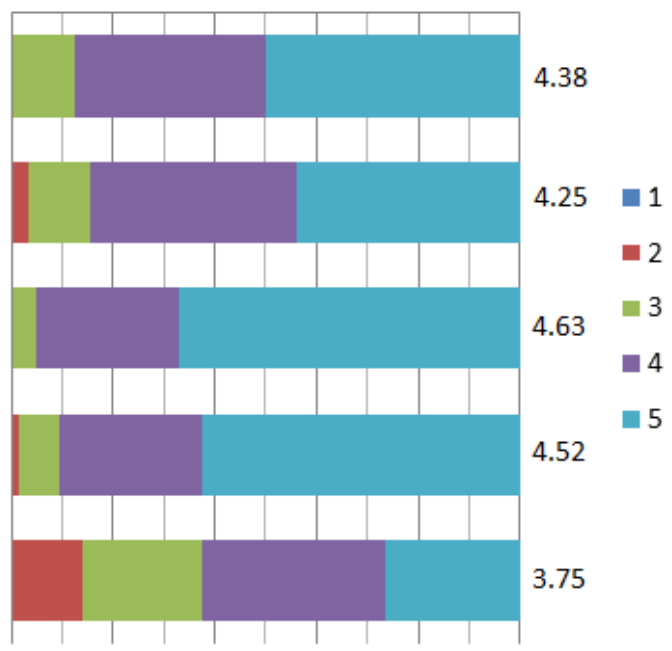

Figure 4. Results obtained from questionnaire \#3, Part B (soft skills acquisition).

Do you consider that you worked in a team?

Have you felt comfortable working in a team?

Have you looked for information for the development of the activity?

Have you felt comfortable looking for information?

Have you used new technologies (computer support) for the development of the activity?

Have you felt comfortable using new technologies?

Do you think that you have been responsible during the development of the activity?

Have you felt comfortable being responsible during the development of the activity?

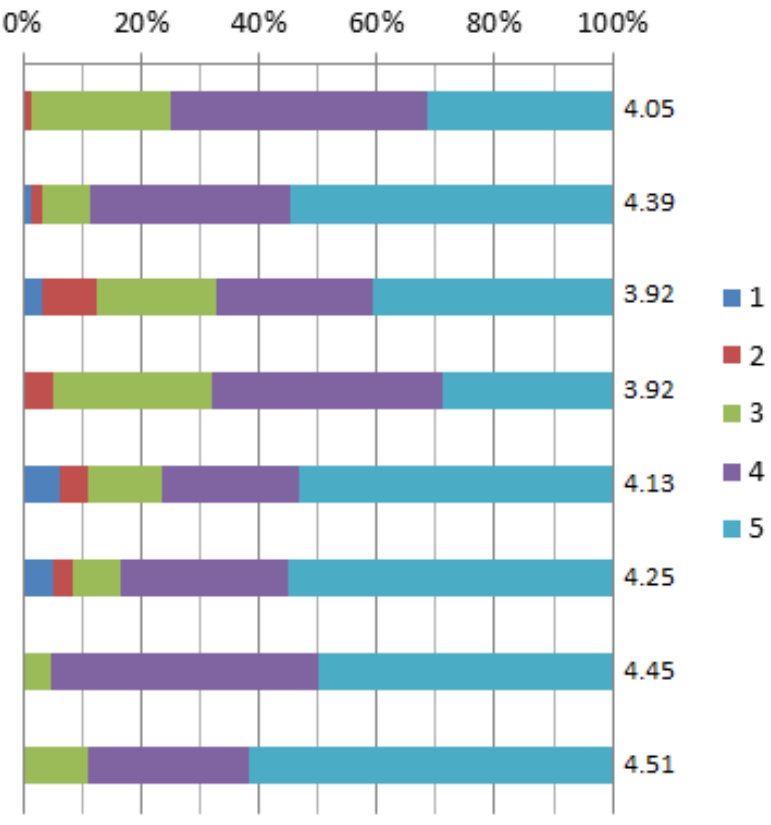

